\title{
Early Minds: a pilot randomised controlled trial of a mindfulness program in early learning centres
}

Maya Yaari ${ }^{1}$, Jane Sheehan ${ }^{2}$, Frank Oberklaid ${ }^{1,3}$ and Harriet Hiscock ${ }^{2,3^{*}}$

\begin{abstract}
Background: Optimal mental health is critical for a child's learning and academic functioning. As a universal service, early education centres play an important role in promoting children's mental health. Social-emotional learning programs are efficacious in reducing behavioural difficulties, enhancing competence, and improving learning abilities. Mindfulness practices, known to promote health and wellbeing in adults, have been adapted to education programs for younger populations, including pre-school children. Despite an increasing use of mindfulness-based programs in pre-school settings, there is a limited number of randomised trials and paucity of data on implementation fidelity of these programs. 'Early Minds' is a mindfulness-based program developed by Smiling Mind for 3-5-year-old children. This paper describes a protocol of a pilot randomised control trial, evaluating the implementation of the program in early learning centres (ELCS, i.e. pre-schools) in Melbourne, Australia. The primary aim of this pilot study is to examine the feasibility, acceptability, and fidelity of the program. The secondary aims are to assess the acceptability of the design and measures and to investigate preliminary impacts of the program on child social-emotional outcomes.

Methods: A convenience sample of six ELCS are recruited. Participants include educators, children, and their parents from 3- and/or 4-year-old ELC rooms. Upon completion of baseline surveys, rooms are randomly allocated to intervention and control arms by an independent statistician. 'Early Minds' is designed in a flexible delivery manner; meditations and activities are completed at least three times a week. Educators are trained in the program and have access to the activities and meditations on an app. Parents are encouraged to practice with their children at least three times a week. Educators document implementation fidelity throughout the 8 weeks of the program. Parents and educators complete follow-up surveys at 3 and 12 months post-randomisation, capturing feasibility and acceptability, child social-emotional behaviour and sleep, and educator, parent, and family wellbeing outcomes.

Discussion: This pilot study is the first to assess a mindfulness-based program in ELCs in Australia. Data on feasibility and acceptability, implementation fidelity, and potential impact on children's behaviour will inform the design of adequately powered evaluation trials.
\end{abstract}

Trial registration number: Australian New Zealand Clinical Trials Registry, ACTRN12618000435280. Date registered 26 March 2018.

Keywords: Social-emotional learning, Mindfulness, Pre-school, Early education, Wellbeing, Implementation Fidelity

\footnotetext{
* Correspondence: harriet.hiscock@mcri.edu.au

${ }^{2}$ Centre for Community Child Health, Royal Children's Hospital; Health

Services Group, Population Health Theme, Murdoch Children's Research

Institute, 50 Flemington Rd, Parkville, Victoria 3052, Australia

${ }^{3}$ Department of Paediatrics, University of Melbourne, Flemington Road,

Parkville, Victoria, Australia

Full list of author information is available at the end of the article
}

(c) The Author(s). 2019 Open Access This article is distributed under the terms of the Creative Commons Attribution 4.0 International License (http://creativecommons.org/licenses/by/4.0/), which permits unrestricted use, distribution, and reproduction in any medium, provided you give appropriate credit to the original author(s) and the source, provide a link to the Creative Commons license, and indicate if changes were made. The Creative Commons Public Domain Dedication waiver (http://creativecommons.org/publicdomain/zero/1.0/) applies to the data made available in this article, unless otherwise stated. 


\section{Background}

Young children's mental health has an important role in shaping their learning skills and future outcomes [1-3]. Optimal mental health is achieved not only by eliminating difficulties or symptoms, but also by promoting competence, with optimal mental health being a combination of low difficulties and high competence. Mentally healthy young children are free of not only externalising and internalising symptoms but also succeeding in the cognitive and emotional developmental tasks of their age, gaining skills that lay the foundations for the successful adaptation to future challenges $[4,5]$. These include emotion regulation skills-understanding and managing emotions, social skills-getting along with others and empathising, and executive functioning skills-planning, making decisions, and regulating attention [6]. When young children have mental health difficulties and/or low competence to deal with their emotions, behaviours, and relationships, this impairs their ability to learn and function in school. Evidence shows that anything less than the optimal combination of low difficulties and high competence is associated with poorer learning skills and achievements $[7,8]$. As a universal service, early learning centres (ELCs) and schools play a key role in developing mentally healthy children, and there is increasing recognition of the importance of acquisition of social-emotional skills in early education contexts $[9,10]$. Social-emotional learning (SEL) programs in schools have been shown to improve not only children's wellbeing but also their academic achievements and learning skills [10-12]. Although all children may benefit from interventions that build their social-emotional skills and executive functioning, evidence suggests that those with higher difficulties at baseline benefit the most [10].

Mindfulness refers to a Buddhist meditation practice that cultivates present moment awareness by paying attention to present experience in the present moment, with openness and without judgement [13]. The ability to direct attention and focus on one thing, and an open, nonjudgmental attitude, is developed through the practice of meditation. Mindfulness training has become a common practice in various health settings over the last decades, with robust evidence in clinical adult populations of efficacy in reducing mental health symptoms and improving socio-emotional functioning [14-16] also shown in neural changes in the brain and immune function $[17,18]$.

More recently, there has been increasing use of mindfulness practices with younger populations. The vast majority of interventions have been conducted with middle and high school students, with some evidence of efficacy for neurocognitive, psychosocial, and psychobiological outcomes [10,19-21]. Mindfulness programs have recently been extended and adapted to the pre-school age, implemented mostly in early education settings. Results from controlled and non-controlled studies with preschoolers show initial promise in reducing externalising symptoms and behavioural problems and hyperactivity [22-25] and in promoting self-regulation skills and executive functions [25-32], prosocial behaviour [22, 28], and language and reading skills [26]. Notably, most studies involving mindfulness practice with children are not randomised control trials and have substantial methodologic limitations, with small sample sizes and potentially biased reported outcomes $[19,21]$. Thus, despite some evidence of efficacy, with increasing delivery of programs, there is still a practice-research gap, calling for a stronger evidence base for these programs. Additionally, the literature on programs to improve developmental outcomes and mental health shows that there is considerable variability in the actual delivery of programs in real-life conditions [11, 33]. Implementation fidelity, i.e. the extent to which the program is delivered in the way it was designed, is critical for its efficacy and can also help to understand which elements of the program work for whom and in which contexts. There is a paucity of data on implementation fidelity for mindfulness programs in educational settings [34].

\section{The Early Minds program}

The Smiling Mind Education Program (SMEP) is described by the Smiling Mind organisation as a preemptive mental health and wellbeing curriculum, designed to provide accessible and flexible mindfulness educational resources for primary and secondary school teachers, students, and parents. The program includes training modules and a manual for educators, access to the activities and meditations via the Smiling Mind website and app, and a resource guide for parents. The topics covered in the program include awareness, attention, the senses, savouring, movement, recognising emotions, managing emotions, self-compassion, optimism, strengths, gratitude, making decisions, setting goals, empathy, acts of kindness, positive relationships, positive communication, a curious mind, growth mindset, and resilience [35].

An evaluation of an 8-week implementation of the SMEP [36], involving 12 Victorian primary and secondary schools, 1853 students, and 104 teachers, yielded promising results for both teacher and student outcomes. In this controlled trial, at 8 weeks post-intervention, students in SMEP reported a significant increase in their wellbeing and sleep quality, improved sense of safety at school, and reduced classroom disruptions, compared to control group peers. Students reporting greater distress at baseline tended to report greater benefits of the program. Teachers in the SMEP reported improved concentration, sleep, and wellbeing and reduced stress and tension [36]. 
Based on the success and uptake of the program in primary and secondary schools, Smiling Mind, together with Early Childhood Australia, psychologists and learning experts developed the Early Minds program - a version of the SMEP adapted for pre-schoolers. The adaptation to the pre-school years included simplifying the topics, aligning them with the Australian Early Years Framework [37], and developing short meditations and additional activities that are more suitable and engaging for young children. Two versions of the program exist-one for 3-4-year-old children and one for the 5-6-year-old children. The simplified topics in the Early Minds program include the following: Who am I, Me and My World, At My Best, I love to Learn, and Finding My Voice. Each topic includes one meditation, one mindfulness activity, and two mindful movement activities. Mediation is a formal mindfulness practice, bringing the attention to a point of focus-e.g. focusing on breathing; mindfulness activity is considered an informal practice, through which mindful awareness is brought into daily activities and tasks by engaging all senses and focusing all the attention on the task-e.g. drawing your family while paying attention to the feeling in the hand and the sounds created by using pencil and paper, the colours on the page, and the feeling and thoughts occurring while drawing; mindful movement activities are 'movement meditations', which combine elements of formal and informal mindfulness practice-e.g. imitating and learning each other's or animal movements while becoming aware to the sensations and feelings of the different movements. Smiling Mind and Early Childhood Australia have enlisted the Murdoch Children's Research Institute (MCRI) to conduct an independent evaluation of the Early Minds program pilot in early learning centres (ELCs) in Melbourne, Victoria.

\section{Aims and objectives}

The primary objective is to evaluate the feasibility, acceptability, and implementation fidelity of the Early Minds program in six Melbourne ELCs. The secondary objectives are to pilot measures of educator and parentreported child outcomes and investigate preliminary impacts of the program on child, parent, and educator wellbeing and family functioning compared to children and families who do not receive the program. Results of the study may be used to inform the design of a largescale trial.

\section{Overall study design and setting}

This is a pilot cluster randomised controlled trial, evaluating the implementation of the 8-week Early Minds program by Smiling Mind within ELC rooms compared to standard ELC curriculum. The study involves three points of data collection: baseline and 3- and 12-month post-randomisation follow-up. Parents and educators complete study surveys at baseline, 3 months, and 12 months. Recruitment and training are conducted by Smiling Minds, and the data collection and evaluation are conducted by MCRI. Educator mindfulness-based knowledge, user experience, competence, and actual use of the program inform feasibility, acceptability, and implementation fidelity. Acceptability of the design and measures is assessed by the response rates of educators and parents and completion of the surveys and inform larger trials. Children's socio-emotional functioning, sleep, and behaviour, reported by parents and educators, and educator and parent wellbeing will indicate potential outcomes of the program.

\section{Methods and analyses \\ Setting}

This is a community-based study, set in six ELCs, representing a sample of convenience in the Melbourne metropolitan area. Within each ELC, children are divided into rooms, based largely on their age at the start of the calendar year, i.e. 3-year-old or 4-year-old rooms.

\section{Participants}

Participants are educators within the 3- or 4-year-old rooms at ELCs recruited by Smiling Mind, children who attend the rooms, and their parents. Centres where the majority of families are non-English speaking or with fewer than 15 children per room are not eligible to participate. Children are excluded if their parent's English language skills preclude their ability to provide informed consent and complete the study surveys, written at a grade 6 reading level.

\section{Timeline (see Fig. 1).}

This study involves three points of data collection: baseline and 3- and 12-month post-randomisation follow-up. Randomisation takes place after baseline data collection.

\section{ELC recruitment}

Recruitment of the ELCs is conducted by Smiling Mind. Following discussions by Smiling Mind with potential ELC Directors regarding the requirements and time commitments involved and assessing eligibility, an agreement is signed with interested centres. Following the ELC recruitment, the research team visits the centre and describes the study procedures to the educators who then sign a Memorandum of Understanding, agreeing to participate in the study. Educators then complete the baseline survey, reporting demographic information and their current experience and knowledge of mindfulness.

\section{Child and parent recruitment}

All families of children in participating rooms receive information letters, advising that their ELC is participating 


\section{CONSORT FLOW DIAGRAM}

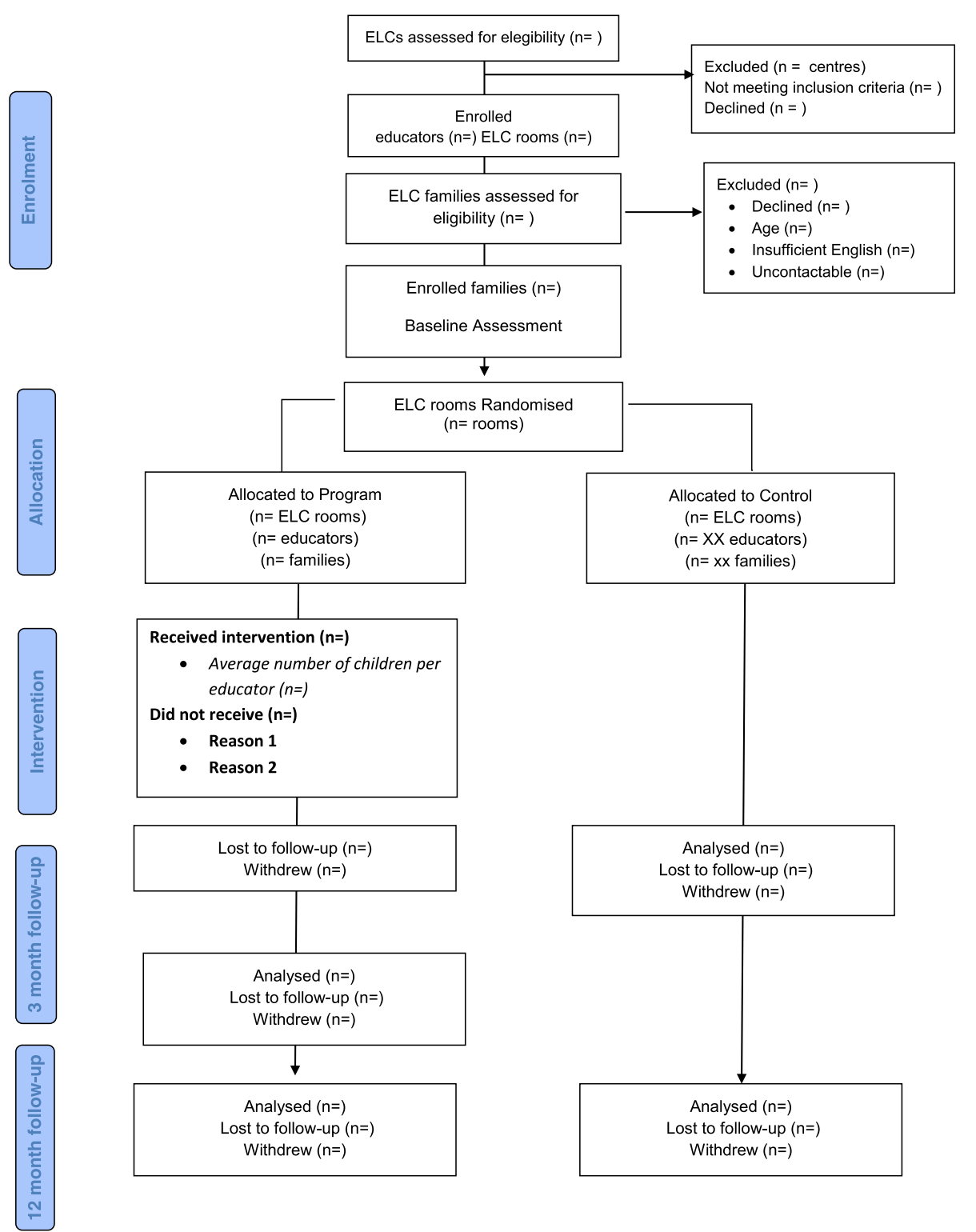

Fig. 1 Consort flow diagram

in the mindfulness evaluation study, that some educators will be trained in the program and others will not, that the trial intervention will go ahead regardless of child/ parent participation in the evaluation study, and that the research team will contact the parents to explain more. An 'opt-out' approach is used, and parents are asked to return their 'opt-out' slip to their ELC if they do not want to be contacted by the study team. If parents do not opt-out within 2 weeks, the centre provides the research team with the family's contact details and the research team telephone the family to provide further details and assess eligibility. Following this telephone call, interested and eligible parents are sent the study information statement, consent form, and baseline survey via post or email. Upon receipt of the parent survey and consent, the child's educator is emailed a link to a baseline survey to complete for this child.

\section{Randomisation of classes}

Upon receiving the completed baseline parent and educator evaluation and child surveys, an independent research assistant randomises ELC rooms to either the program/ intervention group or the usual care/control group, stratified by ELC room age (i.e. 3- or 4-year-old room) to ensure younger age rooms are represented in both the program and usual care groups. Children and educators 
are randomised to the same arm as their room. The independent research assistant conducts the randomisation by selecting a random seed and running a random number sequence using syntax written by an independent statistician. Only educators within the intervention arm are trained in the intervention to reduce contamination in control rooms, particularly if one ELC has an intervention and a control group. Educators and families receive letters to inform them of their group allocation; thus, participants are not blind to allocation. Study staff who are responsible for communication with ELCs and parents are not blind either. However, quantitative analyses will be conducted by research team members who have access only to deidentified data and thus will remain blind to group allocation throughout the analyses.

\section{Intervention}

\section{Training}

Educators' training consists of two $1 \mathrm{~h}$ online learning modules. The first module provides an introduction to mindfulness and the benefits of regular practising. The second module provides educators with a practical approach to teaching simple mindfulness activities to children aged 3-5 years old. Manuals to support implementation are provided to participating educators as well as access to meditations and activities on the Smiling Mind app.

\section{Delivery}

The program is delivered by educators over 8 weeks of a school term, at least three times a week. The program includes guided meditations, activities in which mindful attention is practiced in daily activities and mindful movement activities. Activities take 2-15 min each, and the program is designed to be flexible with educator's choice of activities and how frequently beyond the recommended three sessions per week they are implemented. Parents of children in the intervention arm are provided with a written guide, which includes background information about mindfulness and possible befits of using mindfulness with pre-school age children. Parents are also provided with access to the program meditations and activities on the Smiling Mind app and are encouraged to practice at home with their child at least three times a week.

\section{Outcomes}

Primary outcomes are program feasibility, acceptability as reported by educators and parents, and implementation fidelity as reported by educators. Secondary outcomes are acceptability of the study design and measures by educators and parents, child social-emotional behaviour and sleep as reported by educators and parents, and educator and parent wellbeing.

\section{Measures (see Table 1) \\ Baseline}

Before randomisation, all parents and educators complete a baseline survey including demographic data, their mindfulness knowledge and/or practice (Cognitive and Affective Mindfulness Scale), wellbeing (Depression Anxiety and Stress Scales), and sleep (Longitudinal Study of Australian Children Study). Parents and one educator (who knows the child best) also complete a survey regarding the child's social-emotional behaviour (Strengths and Difficulties Questionnaire, Affective Reactivity Index, Childhood Executive Functioning Inventory, Approaches to Learning) and sleep (Paediatric Sleep Questionnaire). Parents are also asked about their relationship with the child (PEDS-QL Family Impact Module). Educators are asked about their relationship with children in the room as a proxy of class climate (Student-Teacher Relationship Scale).

\section{Implementation fidelity}

During the 8 weeks of the program, participating educators in the intervention group are asked to complete a daily fidelity checklist. This checklist documents for each activity/meditation the group size (whole group or small group), to what extent it was completed (all, partial), whether children were distressed by the activities (yes/no), and number of times the activity was done that day.

\section{Educator program evaluation surveys}

At 3- and 12-month post-randomisation, all educators complete an evaluation survey, repeating the baseline assessment of their knowledge and practice of mindfulness, wellbeing, and class climate. Educators in the intervention group are asked about their use and experience of delivering the program.

\section{Parent surveys}

At 3- and 12-month post-randomisation, all parents complete a survey, repeating the baseline measures of their child's social-emotional behaviour and sleep, their own mindfulness and wellbeing, and their parent-child relationships. Parents in the intervention group are asked about their use of the program meditations and activities via the Smiling Mind app and their experience of using them.

\section{Educator/child surveys}

At 3-month post-randomisation, educators from both groups repeat the baseline measures on the child's social-emotional behaviour and sleep.

Educator and parent surveys are completed online via a web link to Research Electronic Data Capture (REDCap), an online tool, used to build and manage online surveys and databases, which is hosted on a 
Table 1 Study measures

Construct
Socio-demographic information
Program feasibility, acceptability,
and fidelity

User experience

Evaluation of implementation

Fidelity

Knowledge and use of mindfulness theory and techniques

Parent and educator measures

Class climate/teacher-student relationships

Dispositional mindfulness

Subjective wellbeing

Child-related measures

Child social/emotional behaviour

Child irritability

Child sleepiness childhood educator

Parent: family composition, parental education and age, language spoken at home, child age

Study-designed questions assessing use of the program, best and worst aspects of the program, continued use of the program, recommendation of the program to others

Study-designed questions assessing usefulness of the program, implementation of the program, barriers to using the program, fidelity to the program, quality of training in the program, comments about the program

Study-designed questions assessing daily implementation of activities undertaken by educators

Study-designed questions assessing previous/current training in and use of mindfulness, techniques, length of time, and frequency that they have used mindfulness techniques

Adapted version of the Student-Teacher Relationship Scale short (STRS) [38, 39]: 15-item validated scale designed to assess the individual teacher-student relationship, but adapted for use with whole class $(a>80)$.

\section{Cognitive and Affective Mindfulness}

Scale-revised (CAM-R) [40]: 12-item validated scale measuring the tendency for the respondent to be mindful in daily life, including four components of mindfulness (attention, present-focus, awareness, and acceptance). Higher scores indicate a more mindful disposition.

\section{3 items used by Smiling Mind to assess self-reported wellbeing of adults using the think about your life in general? $(0=$ not at all, $10=$ extremely) \\ - How happy do you generally feel? \\ - How content do you generally feel? \\ - How alert do you generally feel?} SM app/website [41]: Please indicate how each of the following describes your feelings when you

\section{Strengths and Difficulties Questionnaire [42]} 25 -item validated measure assessing child's socio-emotional behaviour, including 5 scales: hyperactivity/inattention, conduct problems, emotional symptoms, peer relationship problems, and prosocial behaviour $(a=.73)$.

Affective Reactivity Index [43]: 6-item validated measure assessing child irritability behaviours (e.g. the child gets angry frequently), responses range from 0 (not true) to 2 (certainly true) $(a>.80$ ).

Selected item from the Paediatric Sleep Questionnaire [44]: Does your/this child have a problem with sleepiness during the day? (yes/no/do not know)

$\begin{array}{lll}\text { Time 1 } & \text { Time } 2 & \text { Time } 3 \\ \text { Baseline } & \begin{array}{l}3 \text { months post- } \\ \text { randomisation }\end{array} & \begin{array}{l}12 \text { months post- } \\ \text { randomisation }\end{array}\end{array}$

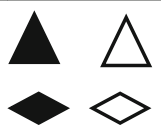

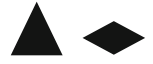

$\Lambda$ $\triangle$ daily, for 8 weeks

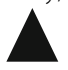

$\Delta \triangle$

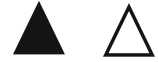

$\triangle \triangle$

$\triangle \triangle \triangle \triangle$

$\triangle \triangle$

$\triangle \triangle \Delta \triangle$

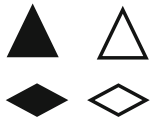

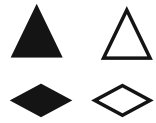
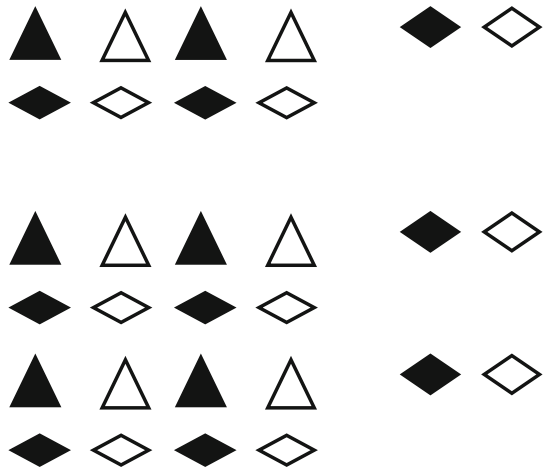<smiles>[CH]</smiles>

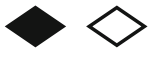


Table 1 Study measures (Continued)

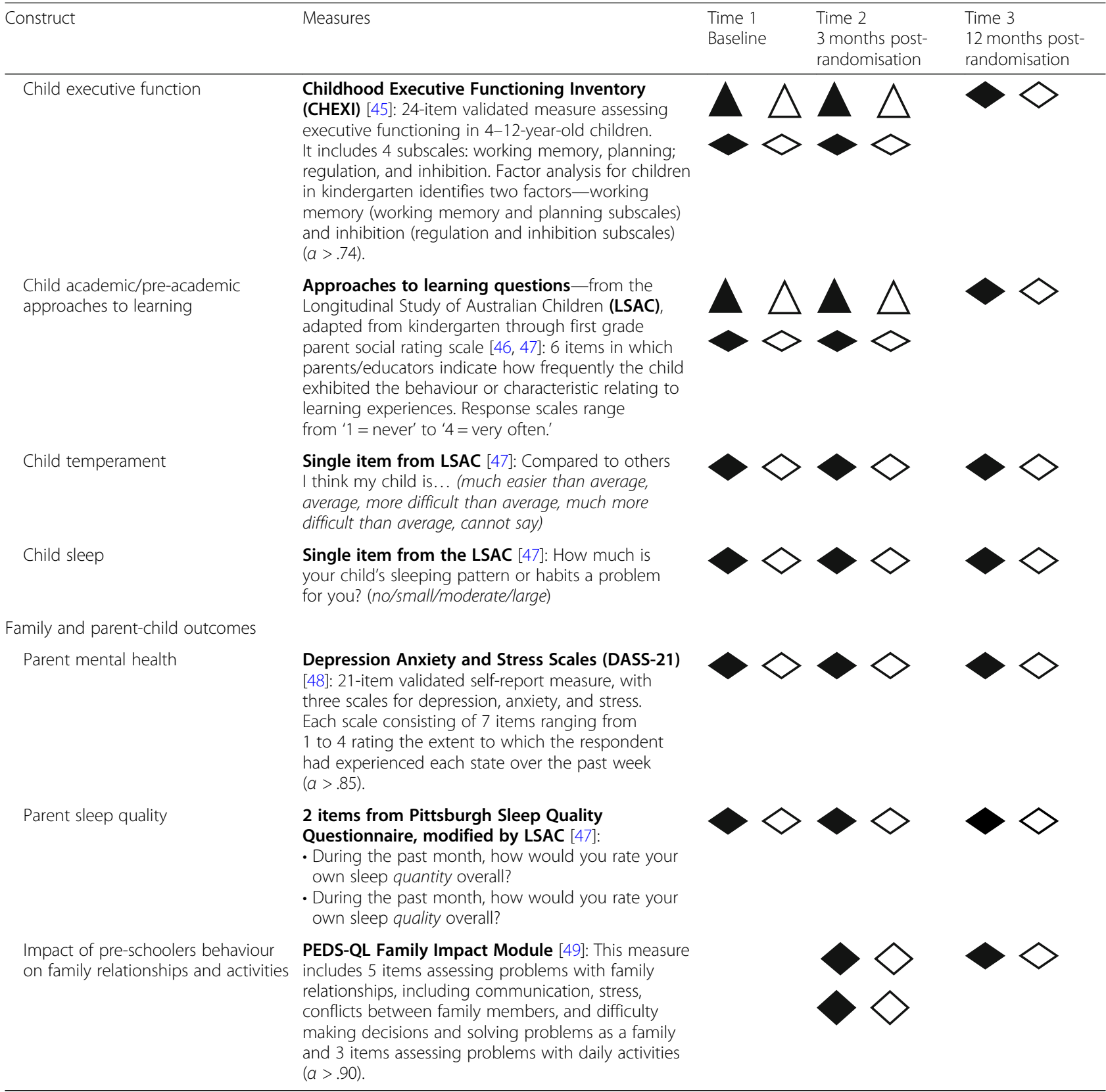

secure MCRI server with restricted access only to researchers involved in the study. Paper version is available if required.

\section{Sample size}

The primary aim of this pilot study is to evaluate the feasibility and acceptability of delivering the Early Minds program within the ELC setting. As such, formal power calculations were not required but a sample of five ELCs with approximately 100 families was deemed sufficient to evaluate the primary aim.

\section{Analysis plan}

Descriptive statistics will be used to collate and report educator and parent responses to open-ended study design questions. Educator's and parent's mindfulnessrelated behaviours change over time; acceptability, frequency of program use, sense of competence, and comments about the program, including challenges and barriers, will be presented.

For quantitative data, the pilot study will use an intention-to-treat analysis. Sample characteristics will be described. Although not a trial designed to determine 
efficacy of the intervention, mean differences in child outcomes between the intervention and control arms will be reported and will provide important data to calculate sample size and power for any future efficacy trial. For the comparisons of intervention versus control, data will be analysed at the individual level, keeping the nested multilevel structure of the clustered individuals intact using multilevel modelling. This statistical method will be used to account for the correlation of responses within clusters (i.e. classrooms). All estimates will be presented with $95 \%$ confidence intervals.

\section{Missing data}

Where available, we will follow the instructions for each specific outcome measure regarding how to deal with missing data. We will then describe the extent of missing data for the variables in our measures and seek to determine identifiable factors associated with missing datai.e. was missingness at random or associated with certain characteristics such as family socio-economic status. We are planning to conduct an intention-to-treat analysis as we aim to describe the possible impacts of the program as it would be delivered in 'real life' in an early childhood setting and collect data from educators on the types and frequencies of activities. In (hypothetical) cases that an educator was allocated to intervention arm but has not done any activity during the intervention period, we will conduct a complementary per protocol analysis.

\section{Ethics and dissemination}

This study has ethics approval from the Human Research Ethics Committee at The Royal Children's Hospital, Melbourne (HREC\#37267), and the Department of Education and Training Research Committee, Victoria (2018_003686). The study has been registered with the Australian New Zealand Clinical Trials RegistryACTRN 12618000435280. A report of results of the study in non-technical language will be submitted to Smiling Mind, summaries of the study will be provided to parents and educators, and a copy of the report will be provided to relevant government departments. The results will be published in the peer-reviewed literature and presented to professional audiences at conferences.

\section{Adverse events}

We do not expect to anticipate risks or inconveniences associated with participation in this study. However, in the case an adverse event occurs, the investigators and the ethics committee would be notified and each case would be addressed as required.

\section{Discussion}

Mindfulness practice has demonstrated efficacy in adult and youth populations in improving mental health, by reducing symptoms and improving competence. Despite the increasing use of mindfulness-based programs with children, there is a paucity of empirical data on the efficacy of these programs for pre-school children, as well as data on implementation fidelity. This is a pilot clustered RCT, conducted in collaboration with Smiling Mind, to assess the feasibility, fidelity, and potential efficacy of a mindfulness-based program for 3-5-year-old children in ELCs in Melbourne. The results of this study will assist to build the evidence base for using mindfulness-based programs in ELCs and can inform the design of adequately powered efficacy trials. Within the scope of a pilot and feasibility study, an assessment of children's outcomes by external, blinded assessors was not feasible and is a limitation in this study. Addition of an objective assessment of executive function, for example, or the classroom environment can provide important additional unbiased evidence in future trials. We will use the data obtained from the study to compare to different indices of minimum clinically important change suggested for the SDQ [50]: difference scores, crossing clinical threshold, reliable change index, and added value scores to inform an a priori decision regarding a measure of clinical significance in a future, fully powered RCT.

\section{Abbreviations \\ ELC: Early learning centre; MCRI: Murdoch Children's Research Institute; SEL: Social-emotional learning; SMEP: Smiling Mind Education Program}

\section{Acknowledgments}

We would like to thank the participating ELC staff and educators, children, and families who are participating in this research. We would like to thank Dr. Addie Wootten CEO of Smiling Mind for her support in detailing the program content. We would also like to thank Ella Sexton and Sonia Khano for their assistance on the project.

\section{Authors' contributions}

MY, JS, and HH contributed to the overall design of the study. MY drafted the manuscript. All authors reviewed and edited the manuscript. All authors read and approved the manuscript.

\section{Funding}

The study was funded by the lan Potter Foundation (Grant number 20170372). The funder is not involved in study design, analyses, or decision to submit the report for publication. Maya Yaari was funded by the Israel Science Foundation Postdoctoral Scholarship, the Hebrew University Postdoctoral Scholarship for Women, and the Hadassah Australia Scholarship. Harriet Hiscock's position was funded by an NHMRC Practitioner Fellowship (No. 607351). Research at the MCRI is supported by the Victorian Government's Operational Infrastructure Support Program.

Availability of data and materials Data will be available upon request.

\section{Ethics approval and consent to participate}

This study has ethics approval from the Human Research Ethics Committee at The Royal Children's Hospital, Melbourne (HREC/17/RCHM/358), and the Department of Education and Training Research Committee, Victoria (2018_003686). All participants sign informed consent forms, in paper or electronically.

Consent for publication

Informed consent is obtained for all participants. 


\section{Competing interests}

FO declares that he holds a position in the board of Smiling Minds. He does not receive any remuneration for this position and is not involved in the day-to-day conduct of the trial, or in analyses of results. The other authors declare that they have no competing interests.

\section{Author details}

${ }^{1}$ Centre for Community Child Health, Murdoch Children's Research Institute, Royal Children's Hospital, 50 Flemington Road, Parkville, Victoria 3052, Australia. ${ }^{2}$ Centre for Community Child Health, Royal Children's Hospital; Health Services Group, Population Health Theme, Murdoch Children's Research Institute, 50 Flemington Rd, Parkville, Victoria 3052, Australia. ${ }^{3}$ Department of Paediatrics, University of Melbourne, Flemington Road, Parkville, Victoria, Australia

Received: 13 December 2018 Accepted: 4 June 2019

Published online: 22 June 2019

\section{References}

1. Shields A, Dickstein S, Seifer R, Giusti L, Dodge Magee K, Spritz B. Emotional competence and early school adjustment: a study of preschoolers at risk. Early Educ Dev. 2001;12(1):73-96.

2. Trentacosta CJ, Izard CE. Kindergarten children's emotion competence as a predictor of their academic competence in first grade. Emotion. 2007;7(1):77.

3. National Scientific Council on the Developing Child. (2008/2012). Establishing a Level Foundation for Life: Mental Health Begins in Early Childhood: Working Paper No. 6. Updated Edition. Retrieved from www. developingchild.harvard.edu.

4. Keyes $\mathrm{CL}$. The mental health continuum: from languishing to flourishing in life. J Health Soc Behav. 2002;43(2):207-22.

5. Kvalsvig A, O'Connor M, Redmond G, Goldfeld S. The unknown citizen: epidemiological challenges in child mental health. J Epidemiol Community Health. 2014;68(10):1004-8

6. Child NSCotD: Childrens-Emotional-Development-Is-Built-into-theArchitecture-of-Their-Brains: Working Paper No. 2. 2004.

7. O'Connor E, O'Connor M, Gray S, Goldfeld S. Profiles of mental health competence and difficulties as predictors of children's early learning. Sch Ment Heal. 2018;10(4):402-16.

8. Antaramian SP, Scott Huebner E, Hills KJ, Valois RF. A dual-factor model of mental health: toward a more comprehensive understanding of youth functioning. Am J Orthopsychiatry. 2010;80(4):462-72.

9. McClelland: SEL intervention in early childhood. 2017.

10. Diamond A, Lee K. Interventions shown to aid executive function development in children 4 to 12 years old. Science. 2011;333(6045):959-64.

11. Durlak JA, DuPre EP. Implementation matters: a review of research on the influence of implementation on program outcomes and the factors affecting implementation. Am J Community Psychol. 2008;41(3-4):327-50.

12. Schonert-Reichl KA, Oberle E, Lawlor MS, Abbott D, Thomson K, Oberlander TF, Diamond A. Enhancing cognitive and social-emotional development through a simple-to-administer mindfulness-based school program for elementary school children: a randomized controlled trial. Dev Psychol. 2015;51(1):52-66

13. Kabat-Zinn J. Mindfulness-based interventions in context: past, present, and future. Clin Psychol Sci Pract. 2003;10(2):144-56.

14. Khoury B, Lecomte T, Fortin G, Masse M, Therien P, Bouchard V, Chapleau M-A, Paquin K, Hofmann SG. Mindfulness-based therapy: a comprehensive meta-analysis. Clin Psychol Rev. 2013;33(6):763-71.

15. Hofmann SG, Sawyer AT, Witt AA, Oh D. The effect of mindfulness-based therapy on anxiety and depression: a meta-analytic review. J Consult Clin Psychol. 2010;78(2):169

16. Creswell JD. Mindfulness interventions. Annu Rev Psychol. 2017;68:491-516.

17. Davidson RJ, Kabat-Zinn J, Schumacher J, Rosenkranz M, Muller D, Santorelli SF, Urbanowski F, Harrington A, Bonus K, Sheridan JF. Alterations in brain and immune function produced by mindfulness meditation. Psychosom Med. 2003;65(4):564-70.

18. Gotink RA, Meijboom R, Vernooij MW, Smits M, Hunink MM. 8-week mindfulness based stress reduction induces brain changes similar to traditional long-term meditation practice-a systematic review. Brain Cogn. 2016;108:32-41.
19. Black DS. Mindfulness training for children and adolescents: a state-of-thescience review. In: Handbook of mindfulness: theory, research, and practice. Edn. New York: Guilford Press; US; 2015. p. 283-310.

20. Mak C, Whittingham K, Cunnington R, Boyd RN. Efficacy of mindfulnessbased interventions for attention and executive function in children and adolescents-a systematic review. Mindfulness. 2018;9(1):59-78.

21. Zenner C, Herrnleben-Kurz S, Walach H. Mindfulness-based interventions in schools-a systematic review and meta-analysis. Front Psychol. 2014;5:603.

22. Singh NN, Lancioni GE, Winton ASW, Karazsia BT, Singh J. Mindfulness training for teachers changes the behavior of their preschool students. Res Hum Dev. 2013;10(3):211-33.

23. Fan AML. Application of dialectical behavior therapy (DBT) to reduce the externalizing behaviors of preschoolers in Hong Kong. In: Dissertation abstracts international section A: humanities and social sciences; 2015. 76(2$A(E)):$ No Pagination Specified.

24. Cohen S. Effects of yoga on attention, impulsivity, and hyperactivity in preschool-aged children with attention-deficit hyperactivity disorder symptoms. J Dev Behav Pediatr. 2018:39:200-19.

25. Viglas M, Perlman M. Effects of a mindfulness-based program on young children's self-regulation, prosocial behavior and hyperactivity. J Child Fam Stud. 2017;27(4):1150-61.

26. Poehlmann-Tynan J, Vigna $A B$, Weymouth $L A$, Gerstein ED, Burnson $C$ Zabransky M, Lee P, Zahn-Waxler C. A pilot study of contemplative practices with economically disadvantaged preschoolers: Children's empathic and self-regulatory behaviors. Mindfulness. 2016;7(1):46-58.

27. Viglas M. Benefits of a mindfulness-based program in early childhood classrooms. In: Dissertation abstracts international section A: humanities and social sciences; 2016. p. 77. 6-A(E).

28. Flook L, Goldberg SB, Pinger L, Davidson RJ. Promoting prosocial behavior and self-regulatory skills in preschool children through a mindfulness-based kindness curriculum. Dev Psychol. 2015;51(1):44-51.

29. Lim X, Qu L. The effect of single-session mindfulness training on preschool children's attentional control. Mindfulness. 2017:8(2):300-10.

30. Razza RA, Bergen-Cico D, Raymond K. Enhancing preschoolers' selfregulation via mindful yoga. J Child Fam Stud. 2015:24(2):372-85.

31. Thierry KL, Bryant HL, Nobles SS, Norris KS. Two-year impact of a mindfulness-based program on preschoolers' self-regulation and academic performance. Early Educ Dev. 2016;27(6):805-21.

32. Thierry KL, Vincent RL, Bryant HL, Kinder MB, Wise CL. A self-oriented mindfulness-based curriculum improves prekindergarten students' executive functions. Mindfulness. 2018;9(5):1443-56.

33. Aboud FE, Prado EL. Measuring the implementation of early childhood development programs. Ann N Y Acad Sci. 2018;1419(1):249-63.

34. Feagans Gould L, Dariotis JK, Greenberg MT, Mendelson T. Assessing fidelity of implementation (FOI) for school-based mindfulness and yoga interventions: a systematic review. Mindfulness. 2016;7(1):5-33.

35. The Mindfulness Curriculum [Available from: https://www.smilingmind.com. au/the-mindfulness-curriculum/].

36. Smiling Minds. Establishing an evidence base for the Smiling Mind Education Program - Preliminary results from a large study conducted by Deakin University and InsightSRC. 2016.

37. Department of Education EaWR. Belonging, being and becoming. The Early Years Learning Framework for Australia. Canberra: Commonwealth of Australia; 2009.

38. Pianta RC. Student-teacher relationship scale: professional manual: psychological assessment resources; 2001.

39. Becker BD, Gallagher KC, Whitaker RC. Teachers' dispositional mindfulness and the quality of their relationships with children in Head Start classrooms. J Sch Psychol. 2017:65:40-53.

40. Feldman G, Hayes A, Kumar S, Greeson J, Laurenceau J-P. Mindfulness and emotion regulation: the development and initial validation of the Cognitive and Affective Mindfulness Scale-Revised (CAMS-R). J Psychopathol Behav Assess. 2007:29(3):177.

41. Tomyn AJ, Cummins RA. Subjective wellbeing and homeostatically protected mood: theory validation with adolescents. J Happiness Stud. 2011;12(5):897-914.

42. Goodman R. Psychometric properties of the strengths and difficulties questionnaire. J Am Acad Child Adolesc Psychiatry. 2001;40(11):1337-45.

43. Stringaris A, Goodman R, Ferdinando S, Razdan V, Muhrer E, Leibenluft $E$, Brotman MA. The affective reactivity index: a concise irritability scale 
for clinical and research settings. J Child Psychol Psychiatry. 2012;53(11): 1109-17.

44. Chervin RD, Weatherly RA, Ruzicka DL, Burns JW, Giordani BJ, Dillon JE, Marcus CL, Garetz SL, Hoban TF, Guire KE. Subjective sleepiness and polysomnographic correlates in children scheduled for adenotonsillectomy vs. other surgical care. Sleep. 2006;29(4):495.

45. Thorell LB, Nyberg L. The Childhood Executive Functioning Inventory (CHEXI): a new rating instrument for parents and teachers. Dev Neuropsychol. 2008;33(4):536-52.

46. U.S. Department of Education. Early childhood longitudinal study KCo-EKNCfES: kindergarten through first grade parent Social Rating Scale (SRS) (Approaches to Learning scale items). 2010. In: Retrieved from https://nces. ed.gov/pubs2010/data/2010070_atl_readme.pdf.

47. Gray M, Sanson A. Growing up in Australia: the longitudinal study of Australian Children. Family Matters. 2005;(72):4-9. https://search.informit.com. au/documentSummary;dn=052395322391224;res=IELFSC.

48. Lovibond PF, Lovibond SH. The structure of negative emotional states: comparison of the Depression Anxiety Stress Scales (DASS) with the Beck Depression and Anxiety Inventories. Behav Res Ther. 1995;33(3):335-43.

49. Varni JW, Sherman SA, Burwinkle TM, Dickinson PE, Dixon P. The PedsQL ${ }^{\text {TM }}$ family impact module: preliminary reliability and validity. Health Qual Life Outcomes. 2004;2(1):55.

50. Wolpert M, Görzig A, Deighton J, Fugard AJ, Newman R, Ford T. Comparison of indices of clinically meaningful change in child and adolescent mental health services: difference scores, reliable change, crossing clinical thresholds and 'added value'-an exploration using parent rated scores on the SDQ. Child Adolesc Mental Health. 2015;20(2):94-101.

\section{Publisher's Note}

Springer Nature remains neutral with regard to jurisdictional claims in published maps and institutional affiliations.

Ready to submit your research? Choose BMC and benefit from:

- fast, convenient online submission

- thorough peer review by experienced researchers in your field

- rapid publication on acceptance

- support for research data, including large and complex data types

- gold Open Access which fosters wider collaboration and increased citations

- maximum visibility for your research: over $100 \mathrm{M}$ website views per year

At $\mathrm{BMC}$, research is always in progress.

Learn more biomedcentral.com/submissions 